\title{
How do we encourage and promote a culture of surgical innovation?
}

The views expressed in this editorial are those of the author and do not necessarily reflect the position of the Canadian Medical Association or its subsidiaries.

T he precise definition of innovation is a frequently debated quandary. Some surgeons describe it as the development of a new idea, method, or device. Others prefer a more nuanced approach: the creation, development, and implementation of a novel product, process, or service. This latter definition is particularly interesting when paired with the aim of improving efficiency, effectiveness, and/or a competitive advantage. An even more bold definition proposes innovation as a disruptive technology that brings about landscape-shifting change and is typically driven by science and technology. ${ }^{1}$

When applied to any and all domains (surgical or otherwise), "invention" is only the first component in the pathway toward true innovation. Perhaps the best description of the totality of this process surrounds the concept of moving from " 0 to $100 . "$ " The initial step from " 0 to 1 " represents the inception of a disruptive innovation that has the potential to alter a given field. The subsequent progression from " 1 to 100 " incorporates incremental evolution (e.g., globalization and mimicry) of that disruption over time. ${ }^{2}$ Although $0-1$ typically consumes less than $0.1 \%$ of the voyage, both elements of the pathway are critical in achieving a persistently disruptive and sustained innovation cycle. Perhaps the best example of the $0-1-100$ relationship, and therefore a superb example of the interplay between both inception and incremental invention, is highlighted by the automobile. Since its humble beginning in 1896 as a truly $0-1$ disruptive technology (i.e., replacing horse-drawn transportation), we have experienced incremental improvements in motor vehicle engineering that have now returned us to the precipice of another potentially $0-1$ disruptive innovation within the same space. More specifically, self-driving vehicles requiring no driver input will lead to major shifts in where we live, how we commute, how infrastructure and roads are constructed, how trauma/injury care is delivered, and even how our workplace environments are contemplated (e.g., parking garage utility).

Surgeons are particularly well placed to both recognize these innovation pathways and to engage them. While the fundamental domains of innovation within the health care system remain consistent with other fields (i.e., financial, internal process, new offerings, and delivery models), the daily opportunities for innovation around us are plentiful. Examples might include telemedicine/telehealth, person- alized medicine, retail health clinics, artificial intelligence integration and, of course, the creation of devices within previously unoccupied surgical spaces. Even the fusion and hybridization of a technique and/or an instrument from one specialty to the next may represent a novel incremental invention.

Another reality is that the context of innovation in my world is likely different from that within your world. This not only applies to content differences among surgical specialties, but also is influenced by the unique social, environmental and historical interactions that each of us have previously experienced. It is also interesting to contemplate the unique mentality of surgeons who seek out innovative spaces. These individuals are often self-motivated, exhibit significant mental toughness, ${ }^{3}$ possess the "ability to move from one failure to another with no loss of enthusiasm, ${ }^{4}$ and believe that innovation is central to their core mission and identity as a surgeon and/or surgeon-scientist.

Although it is not an absolute requirement, surgical innovators can benefit immensely from "supercharged" environments that incorporate supportive colleagues; adequate institutional/departmental support (both financial and temporal); and a physical environment conducive to interpersonal collaboration, personal contemplation, and task completion. This latter environmental tool is often forgotten within our hospitals, as each new recruit is crammed into a basement office within a disorganized building that is increasingly overcrowed. The benefits in regards to both efficiency and productivity within carefully curated environments and groups cannot be overstated.

In addition to identifying and studying innovative individuals, we must also ask ourselves how we can best support them. ${ }^{5}$ This is clearly an increasingly challenging endeavour in a current environment of persistently more frequent obstacles within both the university/academic and provincial public health care settings. More directly, many of our universities have become stagnant in regards to identifying and supporting those with innovative potential and track records of sustained productivity. Furthermore, many of our public health care systems are limited by increasingly restricted budgets and provincial patient volume mandates that are not infrequently at odds with innovative mindsets and practices. This is perhaps why it is critical to reconsider both generous innovation granting opportunities by many of our provincial 
governments, as well as public-private partnerships that support and foster innovation. ${ }^{1}$

Despite these challenges, surgeons from varying practice formats in all areas of the country must continue to encourage, support, and strive for innovation within our (and our colleagues') surgical practices. Our patients will be better off for it, both now and in the future.

\section{Chad G. Ball, MD, MSc; Edward J. Harvey, MD; Mohit Bhandari, MD}

Affiliations: Coeditors-in-chief, Canadian fournal of Surgery (Ball, Harvey); and the Department of Surgery, McMaster University, Hamilton, Ont (Bhandari).

Competing interests: E.J. Harvey is the cofounder and head of medical innovation of NXTSens Inc.; the cofounder and chief medical officer of MY01 Inc., and Sensia Diagnostics Inc.; and the cofounder and director of Strathera Inc. He receives institutional support from J \& J DePuy Synthes, Stryker, MY01, and Zimmer. M. Bhandari declares grants paid to his institution from Canadian Institutes of Health Research, National Institutes of Health, the Michael G. DeGroote Institute for Pain Research and Care, and Physicians' Services Incorporated Foundation. He also declares consulting fees from Pendopharm, Bioventus and Acumed, and he is an advisory board member of the Mayo Clinic Core Center for Clinical Research. None declared by C.G. Ball.
Content licence: This is an Open Access article distributed in accordance with the terms of the Creative Commons Attribution (CC BYNC-ND 4.0) licence, which permits use, distribution and reproduction in any medium, provided that the original publication is properly cited, the use is noncommercial (i.e., research or educational use), and no modifications or a daptations a re $\mathrm{m}$ ade. S ee: $\mathrm{h}$ ttps://creativecommons. org/licenses/by-nc-nd/4.0/

Cite as: Can J Surg 2021 November 18; 64(6). doi: 10.1503/cjs.019021

\section{References}

1. Harvey E. Ed Harvey on innovation. Interviewed by Chad Ball and Ameer Farooq, Cold Steel: Canadian Fournal of Surgery Podcast; 2021 June 4. Available: https://soundcloud.com/cjs-podcast/ e85-ed-harvey-on-innovation (accessed 2021 Nov. 4).

2. Theil P. Zero to one: Notes on startups, or how to build the future. New York: Crown Business, Random House; 2014.

3. Percy DB, Streith L, Wong H, et al. Mental toughness in surgeons: Is there room for improvement? Can $\mathcal{F}$ Surg 2019;62:482-7.

4. Churchill WS. Churchill by bimself: in his own words. London: Rosetta Books; 2013.

5. Bhandari M. Mohit Bhandari on surgical trials, productivity and presentations. Interviewed by Chad Ball and Ameer Farooq, Cold Steel: Canadian Fournal of Surgery Podcast; 2020 June 12. Available: https://soundcloud.com/cjs-podcast/e20-mohit-bhandari-on-surgical -trials-productivity-and-presentations (accessed 2021 Nov. 4). 